\title{
Economic system optimization of air-cooled organic Rankine cycles powered by low-temperature geothermal heat sources ${ }^{\text {th }}$
}

\author{
Daniël Walraven $^{\mathrm{a}, \mathrm{c}}$, Ben Laenen ${ }^{\mathrm{b}, \mathrm{c}}$, William D'haeseleer ${ }^{\mathrm{a}, \mathrm{c}, *}$ \\ ${ }^{a}$ University of Leuven (KU Leuven) Energy Institute - TME branch (Applied Mechanics and Energy Conversion), \\ Celestijnenlaan 300A box 2421, B-3001 Leuven, Belgium \\ ${ }^{b}$ Flemish Institute for Technological Research (VITO), Boeretang 200, B-2400 Mol, Belgium \\ ${ }^{c}$ EnergyVille (Joint Venture of VITO and KU Leuven), Dennenstraat 7, B-3600 Genk, Belgium
}

\begin{abstract}
In this paper, an economic system optimization of an air-cooled organic Rankine cycle, powered by geothermal heat, is performed. The goal is to find the configuration of the ORC which gives the highest possible net present value for the project. The cycle parameters, heat-exchanger geometry and air-cooled-condenser geometry are optimized together. The developed method is applied to a case study, based on a Belgian geothermal project, after which the most important parameters are varied. It is shown that the air-cooled condenser is a crucial component from both a thermodynamic and economic point of view. The discount rate, electricity price, brine-inlet temperature and annual electricity price evolution have a strong influence on the configuration and efficiency of the ORC and on the economics of the project.
\end{abstract}

Keywords: ORC, geothermal, air-cooled condenser, economics, optimization

\section{Introduction}

Low-temperature geothermal heat sources are widely available [1], but the heat-to-electricity conversion efficiency is low due to the low temperature. Much research has been performed to maximize this conversion efficiency by the use of organic Rankine cycles (ORCs) [2-5], but most of these studies focus on maximizing the thermodynamic conversion efficiency while ignoring the economics of the power plant. Only a limited number of studies are available in the open literature which perform a detailed economic optimization of organic Rankine cycles. Quoilin et al. [6] have minimized the specific cost of small ORCs. Recently Astolfi et al. [7] have used the same objective function for large ORCs powered by geothermal heat.

However, many components of the ORC are often assumed to be ideal or modeled very simplistically; pinch-point-temperature differences are fixed and the condenser temperature is fixed. All these parameters depend in fact on the configuration of the cycle and the choice of the working fluid and have a strong influence on the performance and the total cost of the ORC.

The necessity of taking into account the influence of the sizing of the components has already been investigated in the literature. Madhawa Hettiarachchi et al. [8] have minimized the ratio of the total heat exchanger surface and the net power produced by the cycle of fixed heat-exchanger configurations. Franco and Villani [9] have first optimized the cycle parameters, followed by optimizing the heat exchangers. They have performed an iteration between both optimizations. Walraven et al. [10] have optimized the configuration of shell-and-tube heat exchangers together with the configuration of the cycle.

\footnotetext{
Published version: http://dx.doi.org/10.1016/j.energy.2014.11.048

*Corresponding author. Tel.: +32 163225 11; fax: +32 16322985.

Email addresses: Daniel.Walraven@mech.kuleuven.be (Daniël Walraven), Ben.Laenen@vito.be (Ben Laenen), William.Dhaeseleer@mech.kuleuven.be (William D'haeseleer)
} 
In this paper we go one step further, whereby economics and system optimization are combined to perform an economic system optimization. In such an optimization, the cycle and all the components are optimized together, so that the economic performance of the total installation is maximized. To obtain this goal, all components should be modeled in detail and cost-correlations for all components are necessary.

In our previous work [10] we have already modeled most of the components, except for the cooling system and the turbine. The cooling system is a very important part of the installation, because the conversion efficiency of the cycle is low and a large part of the heat added to the ORC has to be dumped in the condenser. The cooling can be of the dry or the wet type. In this paper we will focus on the dry type which, in contrast to wet cooling, can be used at all locations. Different tube and fin shapes are possible. Correlations for round tubes with plain, louvered, slit and wavy fins exist [11-14]. Often flat tubes are used instead of round tubes. Correlations for plain, louvered and slit fins exist in the literature [15-18]. Flat tubes with plain fins are often used in power plants and this type is implemented in this work, based on the work from Yang et al. [15].

In this paper, a model for an axial turbine [19] and a model for an air-cooled condenser [15] are added to our previous work [10], together with cost-correlations for all the components. The net present value of a case study based on a geothermal project in Belgium is maximized and the influence of different economic parameters are investigated.

\section{Physical model}

\subsection{Organic Rankine cycle}

The cycles can be simple or recuperated, subcritical or transcritical and can have one or two pressure levels. Two examples are given in figure 1, in which the scheme of a single-pressure, recuperated ORC and a double-pressure, simple ORC are shown. All the possible heat exchangers (economizer, evaporator, superheater, desuperheater, condenser and recuperator) are shown in the figure, but are not always necessary.

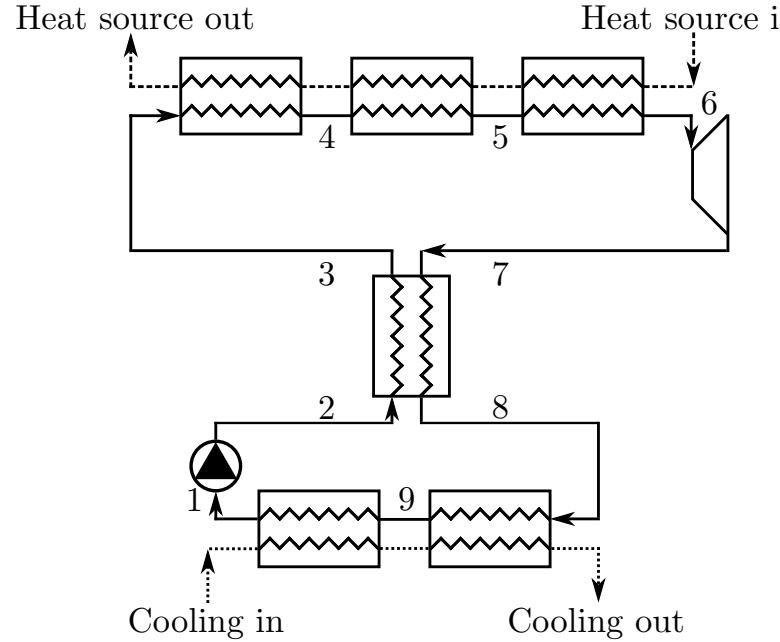

(a) Single-pressure

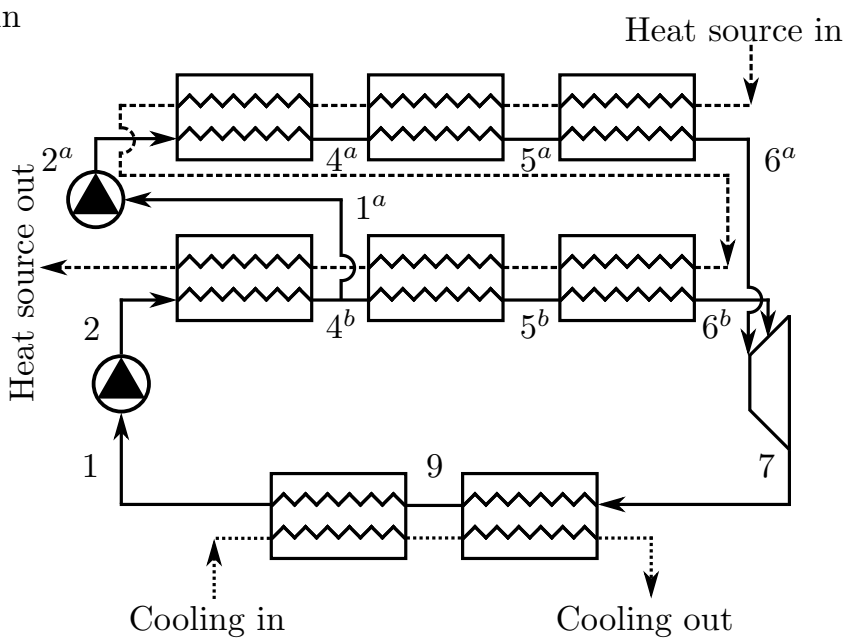

(b) Double-pressure

Figure 1: Scheme of a single-pressure, recuperated (a) and double-pressure, simple (b) ORC.

In all configurations it is assumed that state 1 is saturated liquid and that the isentropic efficiencies of the pump is $80 \%$. More information about the modeling of the cycle can be found in our previous work $[4,10]$. 


\subsection{Air-cooled condenser}

\subsubsection{Geometry}

Different types of air-cooled condensers (ACCs) exist, but in this paper only the A-frame air-cooled condenser with flat tubes and corrugated fins is used. This type is often used in power plants because the pressure drop is lower than the one in ACCs with round tubes [15,20]. Figure 2 shows the geometry of such an A-frame air-cooled condenser and the bundle geometry of flat tubes with corrugated fins.

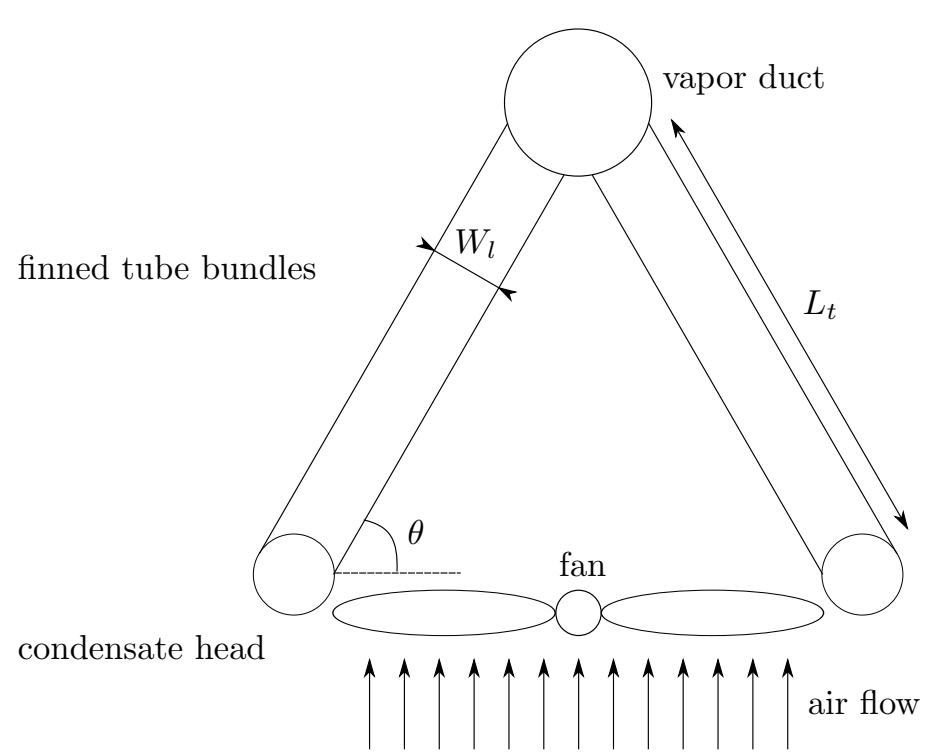

(a) A-frame

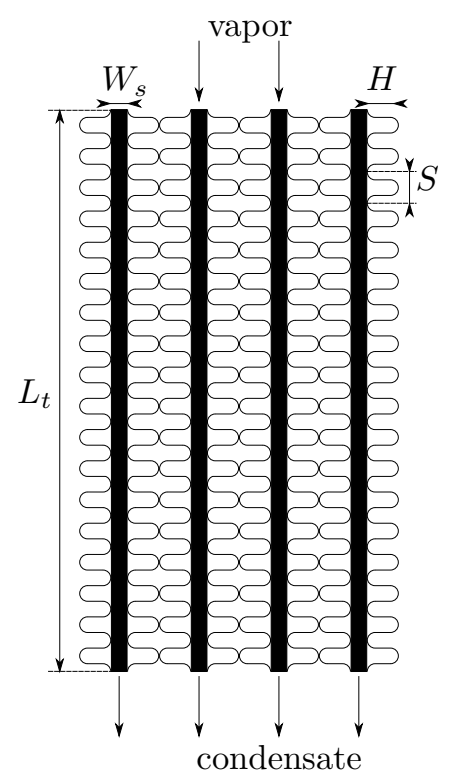

(b) Tube bundle

Figure 2: Geometry of an A-frame air-cooled condenser (a) and the bundle geometry of flat tubes with corrugated fins (b).

The tube-bundle geometry is determined by the tubes' small width $W_{s}$, the fin height $H$, the fin pitch $S$, the tubes' large width $W_{l}$ and the length of the tubes $L_{t}$. In an A-frame ACC the tube bundles are placed at an angle $\theta$ with the horizontal. The vapor/two-phase fluid enters the condenser at the top in the vapor duct, flows down the tubes, in which it condenses, and the condensate is collected at the bottom in the condensate head. A fan at the bottom blows air over the tube bundles.

\subsubsection{Model description}

The correlation of Yang et al. [15] is used to model the heat-transfer coefficient and the pressure drop at the air side of the heat exchanger. The Nusselt correlation is given $\operatorname{as}^{1}$ :

$$
N u=0.05922 R e^{0.9172}\left(\frac{S}{W_{s}}\right)^{0.9993}\left(\frac{H}{W_{s}}\right)^{-0.3706},
$$

with $R e$ the Reynolds number defined as:

$$
R e=\frac{\rho_{a i r} V_{A m i n} W_{s}}{\mu_{\text {air }}}
$$

with $\rho_{\text {air }}$ the density of the air, $V_{A m i n}$ the velocity at the minimum flow area and $\mu_{\text {air }}$ the dynamic viscosity of the air. The fluid properties are all calculated at the average temperature and pressure of the air.

\footnotetext{
${ }^{1}$ Formula (13) in the original paper of Yang et al. [15] gives a Nusselt number which is 10 times to high, which is confirmed in a personal communication by professor Yang.
} 
The heat-transfer coefficient obtained from equation (1) is based on the total heat exchanger surface area, including the area of the fins.

The friction factor while neglecting natural convection is:

$$
f=\frac{238.8552}{2} R e^{-0.6684}\left(\frac{S}{W_{s}}\right)^{-1.4129}\left(\frac{H}{W_{s}}\right)^{-0.1496} .
$$

The factor 1/2 in equation (3) arrives from the fact that Yang et al. [15] developed their correlation for another type of fins. This other type of fins results in a pressure drop which is about twice as high and a heat-transfer coefficient which is about the same as the configuration investigated in this paper [15]. The pressure drop of the air flowing through the tube bundle is then:

$$
\Delta p_{a i r}=f \frac{\rho_{a i r} V_{A \min }^{2}}{2} .
$$

The electrical-power consumption of the fan is calculated as:

$$
\dot{W}_{f a n}=\frac{\Delta p_{a i r} \dot{m}_{a i r}}{\rho_{a i r} \eta_{f a n} \eta_{e l, f a n}},
$$

with $\dot{m}_{\text {air }}$ the mass-flow rate of air, $\eta_{\text {fan }}$ the fan efficiency and $\eta_{e l, \text { fan }}$ the efficiency of the fan engine. The product of the last two parameters is assumed to be $60 \%$.

Equations (1) and (3) are valid for $\theta=60^{\circ}, W_{l}=219 \mathrm{~mm}, W_{s}=19 \mathrm{~mm}$ and for

$$
\begin{aligned}
& 0.06 \leq \frac{S}{W_{s}} \leq 0.16 \\
& 0.75 \leq \frac{H}{W_{s}} \leq 1.25 \\
& 700 \leq R e \leq 14500
\end{aligned}
$$

The correlations of Petukhov and Popov [21] and Gnielinski [22] are used to calculate the pressure drop and heat-transfer coefficient for the single-phase flow in the pipes, respectively. For the two-phase flow of the working fluid in the pipes, the CISE correlation [23], the correlation of Chisholm [24] and the correlation of Shah [25] are used to calculate the void fraction, pressure drop and heat-transfer coefficient, respectively.

\subsection{Turbine efficiency}

Three different types of turbines are used in ORCs: the axial-flow turbine, the centripetal turbine and the radial-inflow, radial-outflow turbine. In this paper, we will focus on the first type because of the availability of correlations. Macchi and Perdichizzi [19] used the Craig and Cox-model [26] to optimize the performance of axial flow-turbines. This resulted in an efficiency prediction of a turbine stage based on the inlet state of the turbine and the isentropic outlet state. The original prediction was given as a figure, which is curve-fitted in Appendix A.

\subsection{Heat exchangers}

The heat exchangers used in this paper are all shell-and-tube heat exchangers because of the availability of correlations for the performance and cost. More information about the modeling and optimization of this type of heat exchangers for the use in ORCs can be found in Walraven et al. [10]. 


\section{Economics}

\subsection{Net present value}

The net present value (NPV) $)^{2}$ is calculated as

$$
\mathrm{NPV}=-C_{E P C}+\sum_{t=1}^{t_{L T}} \frac{I_{t}}{(1+i)^{t}}
$$

with $C_{E P C}$ the engineering, procurement \& construction overnight cost $(\mathrm{EPC})$ of the installation ${ }^{3}, t_{L T}$ the lifetime of the installation, $I_{t}$ the income in year $t$ and $i$ the discount rate. The EPC cost consists of two parts: the cost of the drilling $C_{d r i l l i n g}$ and the cost of the ORC $C_{O R C}$ (see section 3.2). The income in year $t$ can be calculated as:

$$
I_{t}=\dot{W}_{\text {net }} p_{\text {elec }} N-C_{O M},
$$

with $\dot{W}_{n e t}$ the net electric power output, which takes a generator efficiency of $98 \%$ into account, expressed in $\mathrm{MW}_{e}, p_{\text {elec }}$ the price obtained per MWh of produced electricity, $N$ the number of full-load hours per year (an availability of $95 \%$ is assumed) and $C_{O M}$ the cost of operation and maintenance of the powerplant, which is assumed to be $2.5 \%$ of the investment cost of the ORC per year [28].

\subsection{Cost of ORC}

The overnight EPC investment cost of the ORC, $C_{O R C}$, can be calculated as:

$$
C_{O R C}=\sum_{i}\left(f_{M, i} f_{P, i} f_{T, i}+f_{I}\right) C_{E, i},
$$

with $C_{E, i}$ the delivered equipment cost of component $i$ and $f_{M, i}, f_{P, i}$ and $f_{T, i}$ correction factors (all $\geq 1$ ) for non-standard material, pressure and temperatures, respectively. $f_{I}$ is an average installation-cost factor [29]. This installation-cost factor includes the costs for erection, instrumentation and control of the power plant and is about $0.6[29,30]$. Correlations for the equipment $\operatorname{cost} C_{E, i}$ are given in table 1.

\begin{tabular}{lllll} 
Component & Capacity measure & Size range & Cost correlation & Ref \\
\hline Shell-and-tube heat exchanger & $A\left[\mathrm{~m}^{2}\right]$ & $80-4000 \mathrm{~m}^{2}$ & $3.5010^{4}\left(\frac{A}{80}\right)^{0.68}\left[€^{2013}\right]$ & {$[29]$} \\
Centrifugal pump (incl. motor) & $\dot{W}_{\text {pump }}[\mathrm{kW}]$ & $4-700 \mathrm{~kW}$ & $10.5110^{3}\left(\frac{\dot{W}_{\text {pump }}}{4}\right)^{0.55}\left[€^{2013}\right]$ & {$[29]$} \\
Air-cooled heat exchanger & Bare-tube $A\left[\mathrm{~m}^{2}\right]$ & $200-2000 \mathrm{~m}^{2}$ & $1.6710^{5}\left(\frac{A}{200}\right)^{0.89}\left[€^{2013}\right]$ & {$[29]$} \\
Fan (incl. motor) & $\dot{W}_{\text {fan }}[\mathrm{kW}]$ & $50-200 \mathrm{~kW}$ & $1.3110^{4}\left(\frac{\dot{W}_{\text {fan }}}{50}\right)^{0.76}\left[€^{2013}\right]$ & {$[29]$} \\
Turbine & $\dot{W}_{\text {turbine }}[\mathrm{kW}]$ & $0.1-20.0 \mathrm{MW}$ & $-1.6610^{4}+716 \dot{W}_{\text {turbine }}^{0.8}\left[€^{2013}\right]$ & {$[31]$} \\
\hline
\end{tabular}

Table 1: Cost correlation for the different components. The data from Smith [29] and Towler and Sinnott [31] are adapted taking into account that $1 €=1.35 \$$ and with a Chemical Engineering (CE)-index of 564 in July 2013.

Most of the cost correlations in table 1 are valid for carbon steel, for design temperatures between 0 and $100{ }^{\circ} \mathrm{C}$ and for design pressures between 0.5 and 7 bar. Such "normal" designs are good enough for most heat exchangers in a low-temperature ORC. Only the heat exchangers between brine and working fluid work at higher pressures and temperatures and have a higher risk for corrosion. For these heat exchangers, the values of table 1 are adjusted using the above mentioned correction factors; the tubes are made from stainless steel $\left(f_{M}=1.7\right)$, work at higher pressures $\left(f_{P}=1.5\right)$ and at higher temperatures $\left(f_{T}=1.6\right)[29]$. A correction factor $f_{P}=1.5$ is used for the pump. The correlation for the turbine is one for a condensing steam turbine and no pressure-correction factor is used because steam turbines work at higher pressures.

\footnotetext{
${ }^{2}$ In this paper it is chosen to maximize the NPV of the power plant. It is also possible to minimize the Levelized Cost of Electricity (LCOE) [27].

${ }^{3}$ There is a caveat: $C_{E P C}$ is not the total investment cost. Some reflections on the investment cost are given in Appendix B.
} 


\section{Optimization}

The goal of the optimization is to maximize the net present value of the installation. This optimization is performed with the use of the CasADi [32] and WORHP [33] software. The models themselves are developed in Python and the fluid properties are obtained from REFPROP [34], using the system optimization methodology of our earlier work [10].

\subsection{Optimization variables and constraints}

In case of a single-pressure simple cycle, the cycle is determined by the temperature before the turbine, the saturation temperature at the pressure before the turbine, the pressure at the inlet of the pump and the mass flow of the working fluid. The effectiveness of the recuperator is added when a recuperated cycle is used. For double-pressure cycles, the temperature before the second turbine, the saturation temperature at the pressure before the second turbine and the mass flow rate through the second turbine are added. More information about these optimization variables can be found in Walraven et al. [10].

The optimization variables of each shell-and-tube heat exchangers are the shell diameter $D_{s}$, tube-outside diameter $d_{o}$, tube pitch $p_{t}$, baffle cut $l_{c}$ and the distance between the baffles $L_{b, c}$. The lower and upper bounds on these variables and the constraints used in this paper are given in table 2 . We refer again to our previous work [10] for more information.

\begin{tabular}{lcc}
\hline Optimization variable & Lower bound & Upper bound \\
\hline Shell diameter $D_{s}$ & $0.3 \mathrm{~m}$ & $2 \mathrm{~m}$ \\
Tube outside diameter $d_{o}$ & $5 \mathrm{~mm}$ & $50 \mathrm{~mm}$ \\
Relative tube pitch $p_{t} / d_{o}$ & 1.15 & 2.5 \\
Relative baffle cut $l_{c} / D_{s}$ & 0.25 & 0.45 \\
Baffle spacing $L_{b, c}$ & $0.3 \mathrm{~m}$ & $5 \mathrm{~m}$ \\
\hline Ratio of tube diameter to shell diameter $d_{o} / D_{s}$ & $/$ & 0.1 \\
\hline
\end{tabular}

Table 2: Optimization variables and constraints used for shell-and-tube heat exchangers and their lower and upper bounds.

The geometry of the air-cooled condenser is determined by the tubes' small width $W_{s}$, the fin height $H$, the fin pitch $S$, the tubes' large width $W_{l}$, the length of the tubes $L_{t}$ and the angle $\theta$ of the tube bundle with the horizontal, as explained in section 2.2. $W_{l}, W_{s}$ and $\theta$ are fixed and $L_{t}$ is the result of the model. So, $H$ and $S$ are necessary to determine the configuration of the tube bundle. Extra variables are the velocity of the cooling air at the minimum cross section $V_{A m i n}$ and the number of tubes $n_{\text {tubes }}$. A non-linear constraint is used to limit the length of the tubes. The values for the lower and upper bounds are given in table 3 .

\begin{tabular}{lcc}
\hline Optimization variable & Lower bound & Upper bound \\
\hline Fin height $H$ & $14.25 \mathrm{~mm}$ & $23.75 \mathrm{~mm}$ \\
Fin pitch $S$ & $1.14 \mathrm{~mm}$ & $3.04 \mathrm{~mm}$ \\
Maximum air velocity $V_{\text {Amin }}$ & $1.5 \mathrm{~m} / \mathrm{s}$ & $10 \mathrm{~m} / \mathrm{s}$ \\
Number of tubes $n_{\text {tubes }}$ & 1000 & 10000 \\
\hline Tube length $L_{t}$ & $/$ & $20 \mathrm{~m}$ \\
\hline
\end{tabular}

Table 3: Optimization variables and constraints used for the air-cooled condenser and their lower and upper bounds.

\section{Results}

\subsection{Reference case}

In this subsection the parameters of our "reference" case are defined, after which a variation of the parameters is performed. The investigated "reference" case is based on a proposed geothermal demonstration project 


\begin{tabular}{lc}
\hline \multicolumn{2}{c}{ Well parameters } \\
\hline Brine wellhead temperature & $125{ }^{\circ} \mathrm{C}$ \\
Brine production & $194 \mathrm{~kg} / \mathrm{s}$ \\
Consumption well pumps & $600 \mathrm{~kW}$ \\
Cost wells & $27.5 \mathrm{M} €$ \\
\hline
\end{tabular}

\begin{tabular}{lc}
\hline \multicolumn{2}{c}{ Economic parameters } \\
\hline Electricity price & $50 € / \mathrm{MWh}_{e}$ \\
Lifetime plant & 30 years \\
Discount rate & $4 \% /$ year \\
Electricity price increase & $5 \% /$ year \\
\hline
\end{tabular}

\begin{tabular}{lc}
\hline \multicolumn{2}{c}{ Environmental conditions } \\
\hline Average dry bulb temperature & $10.3^{\circ} \mathrm{C}$ \\
Air pressure & $1016 \mathrm{hPa}$ \\
\hline
\end{tabular}

Table 4: Parameters of the reference case

in Belgium and the "reference" parameters are given in table 4. In the next subsections, the influence of many of these parameters on the performance of the ORC is investigated.

In this paper, we only focus on electricity production from the geothermal heat source and do not take into account heating purposes. We should stress that many economic parameters used in this paper are based on the literature and that the economic analysis is therefore not detailed enough to be used for a business plan.

\subsection{Influence of the brine-inlet temperature}

Figure 3 shows the NPV of a simple and a recuperated ORC powered by geothermal heat, depending on the inlet temperature of the brine. The NPV increases with increasing brine inlet temperature, as a consequence of the decreasing specific overnight investment cost of the ORC with increasing brine inlet temperature as shown in figure 4.

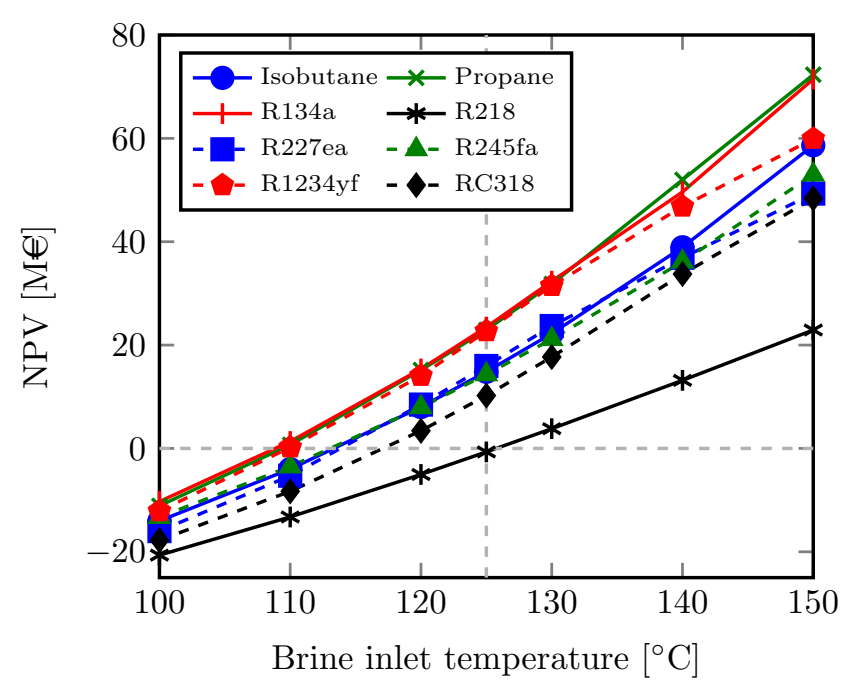

(a) Single-pressure simple cycle

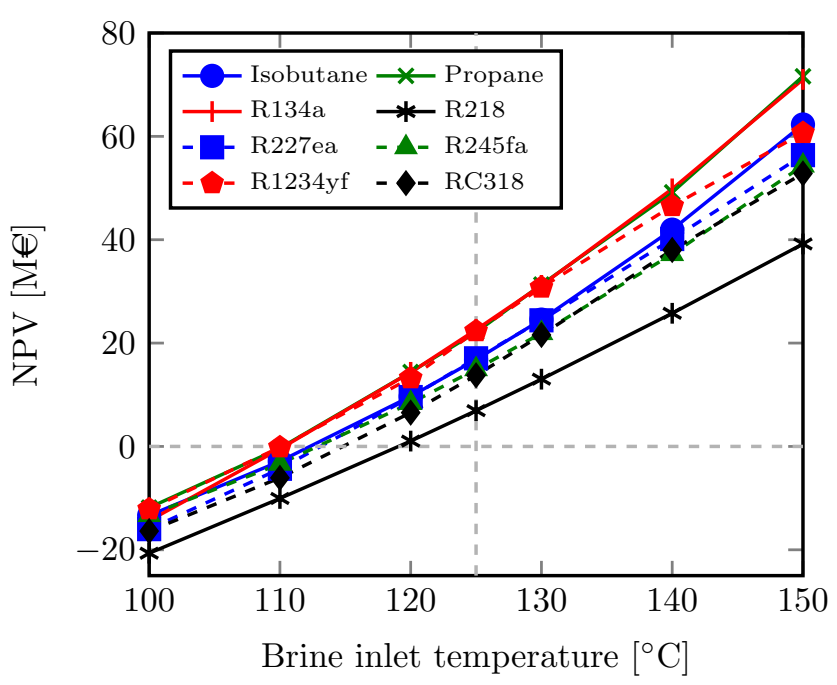

(b) Single-pressure recuperated cycle

Figure 3: Net present value of a single-pressure simple (a) and a single-pressure recuperated (b) ORC powered by geothermal heat, for various thermodynamic-cycle fluids and for varying inlet temperature of the brine.

Two conflicting effects determine the evolution of the specific overnicht ORC investment cost. The absolute cost of the ORC increases with increasing brine inlet temperature (larger turbine and larger heat exchangers), but the net electric power production (see figure 5) also increases. This last effect is larger so that the specific overnight investment cost of the ORC decreases with increasing brine inlet temperature. 


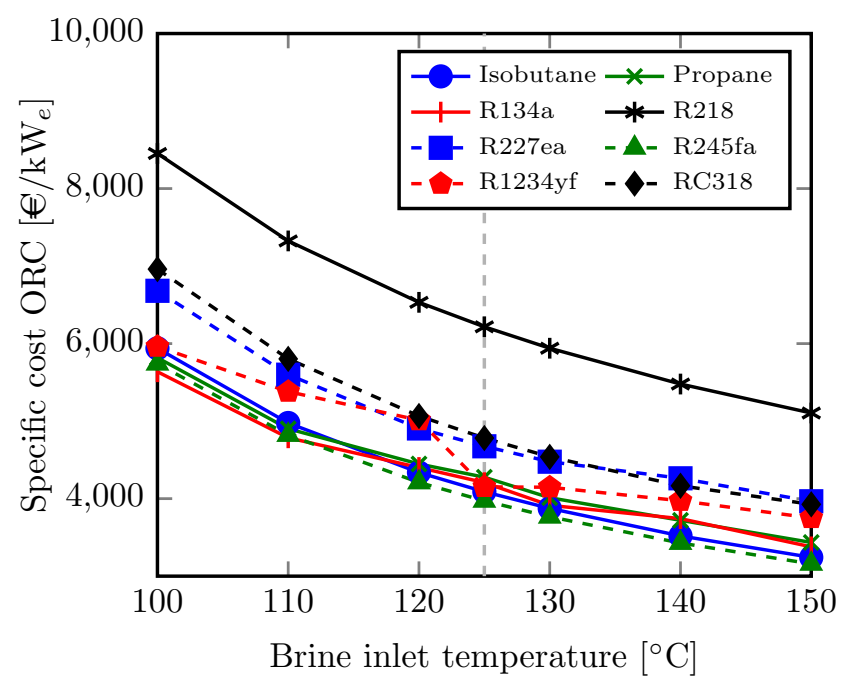

(a) Single-pressure simple cycle

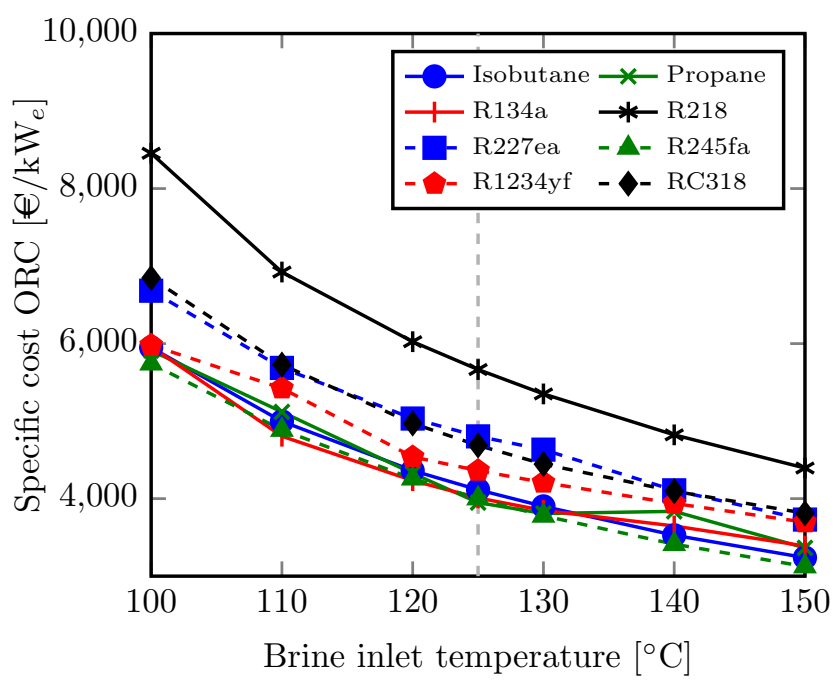

(b) Single-pressure recuperated cycle

Figure 4: Specific cost of a single-pressure simple (a) and a single-pressure recuperated (b) ORC powered by geothermal heat, for various thermodynamic-cycle fluids and for varying inlet temperature of the brine.

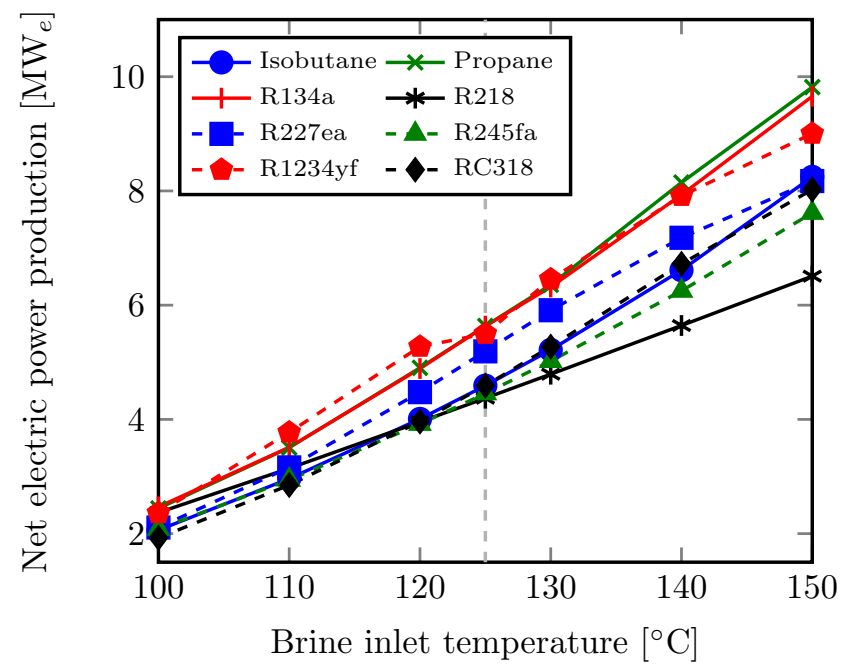

(a) Single-pressure simple cycle

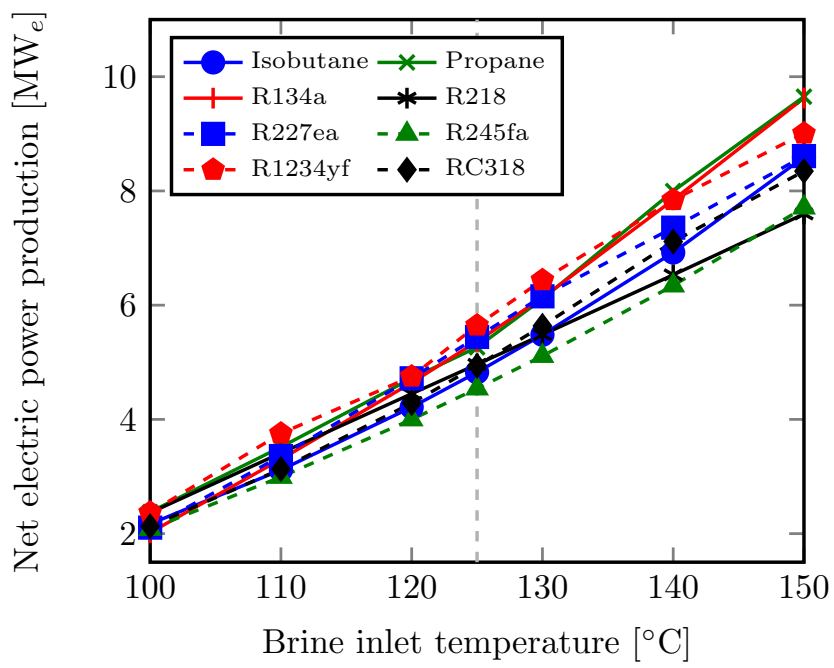

(b) Single-pressure recuperated cycle

Figure 5: Net electric power production of a single-pressure simple (a) and a single-pressure recuperated (b) ORC powered by geothermal heat, for various thermodynamic-cycle fluids and for varying inlet temperature of the brine.

The strong increase of the net electric power production with increasing brine inlet temperature can be explained by two effects. On the one hand, the gross electric power output of the cycle increases with increasing brine inlet temperature (a simple consequence of the thermodynamic efficiency - Carnot). On the other hand, less electrical power (relatively speaking) is needed to drive the fans of the cooling system because the heat added to the cycle is converted more efficiently into mechanical power. So, the gross electric power output increases and the electricity consumption of the auxiliaries decreases (relatively). 
Figures $3 \mathrm{a}$ and $3 \mathrm{~b}$ show the NPV of simple and recuperated cycles, respectively. The addition of a recuperator results in a slightly higher NPV when dry fluids (isobutane, R218, R227ea, R245fa and RC318) are used. This effect is only large enough to be seen in figures $3 \mathrm{a}$ and $3 \mathrm{~b}$ when R218 is used. The NPV is determined by the net power output of the ORC and the cost of it. As seen from figure 5b, the net electric power output of the recuperated cycles is higher than the one of the simple cycles (for the dry fluids). Less cooling is needed in recuperated cycles, so that, when all other conditions are the same, less electrical power is consumed by the fans and the cooling installation can be smaller. These two effects are more important than the extra cost for the recuperator as seen in figure 6a. From this figure it is seen that the ACC is by far the most expensive part of the ORC; about $80 \%$ of the total overnight investment cost of the ORC is credited to the ACC. Other expensive components are the turbine, the economizer and the recuperator. The evaporator is only a small part of the total cost and the cost of the pump is negligible.

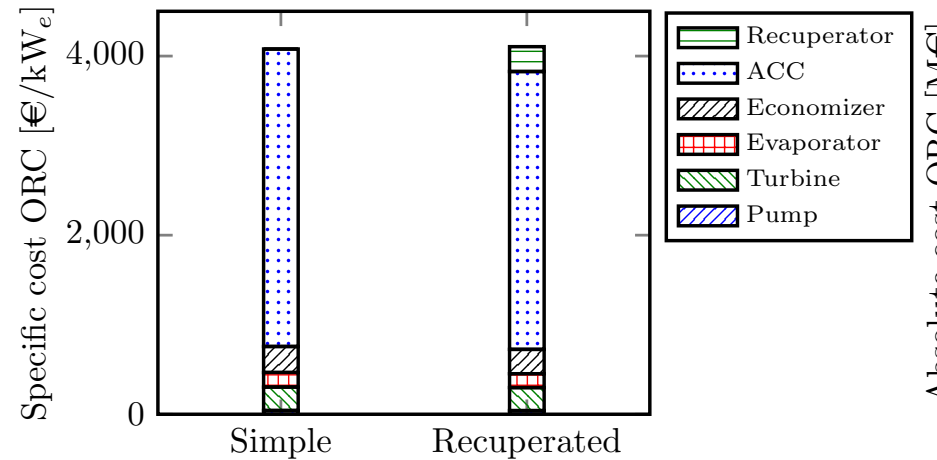

(a) Specific cost

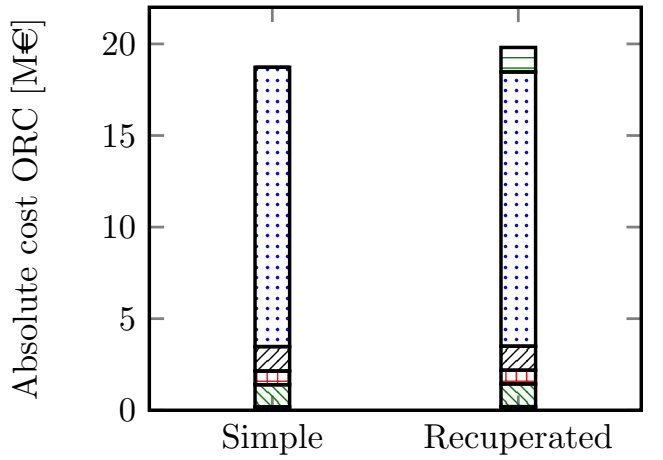

(b) Absolute cost

Figure 6: Distribution of the specific cost (a) and the absolute cost (b) for single pressure, simple and recuperated ORCs with isobutane as the working fluid for a brine inlet temperature of $125^{\circ} \mathrm{C}$. The cost of the superheater is very small in all cases and is not shown in the figure.

Figures $6 \mathrm{a}$ and $6 \mathrm{~b}$ give the distribution of the specific and absolute cost of simple and recuperated ORCs with isobutane as the working fluid. It is chosen to plot the results for this fluid because it is the dry fluid which results in the highest NPV. Figures $6 \mathrm{a}$ and $6 \mathrm{~b}$ show that the specific cost of the optimal simple and optimal recuperated are about the same, while the absolute overnight investment cost of the recuperated ORC is higher than the one of the simple ORC. This means that the net electric power production will be higher for the recuperated cycle than for the simple one. This is achieved by decreasing the condensing temperature of the recuperated ORC in comparison to the simple one.

\subsection{Influence of the brine outlet temperature}

In some cases it is necessary to have a minimum brine outlet temperature to avoid scaling or to use the brine after the ORC for heating. In this paper, we focus only on electricity production and do not take the possible direct use for heating into account, but it can be interesting to see the influence of the minimum allowed brine outlet temperature on the performance of the ORC.

Figure 7 shows the NPV as a function of the minimum brine outlet temperature for single-pressure, simple and recuperated cycles. No effect of the brine outlet temperature constraint is seen for temperatures up to about 50 and $60{ }^{\circ} \mathrm{C}$, which is the brine outlet temperature in case of no constraint, for the simple and recuperated cycles, respectively. For higher minimum brine outlet temperatures, the NPV of both the simple as the recuperated cycles starts to decrease. This decrease is stronger for the simple cycles than for the recuperated ones. It is therefore advantageous to use a recuperator for all fluids, even wet ones, when the constraint on the brine outlet temperature is high. 


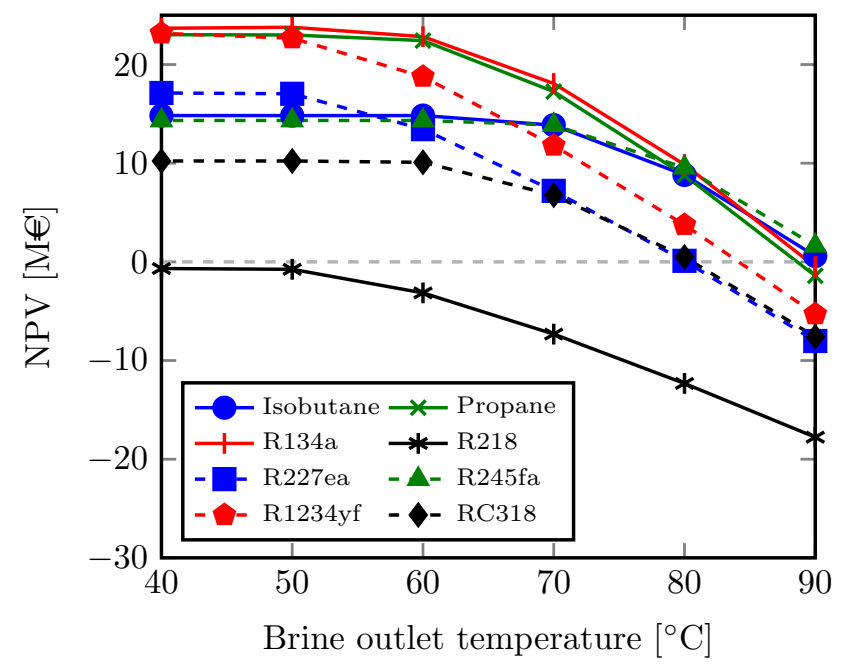

(a) Single-pressure simple cycle

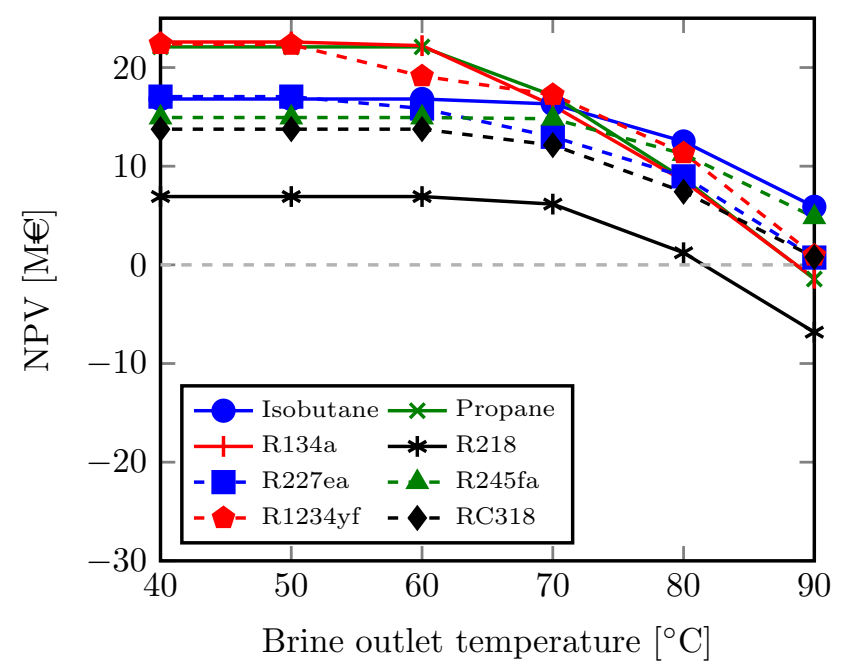

(b) Single-pressure recuperated cycle

Figure 7: Net present value of an ORC powered by geothermal heat, depending on the outlet temperature of the brine. The brine inlet temperature is $125^{\circ} \mathrm{C}$.

In the remainder of this paper, only the results of recuperated cycles will be shown. Simple cycles are in fact recuperated cycles with an effectiveness of the recuperator, which is an optimization variable, of zero. So, recuperated cycles are the most general ones.

\subsection{Impact of 2 pressure levels}

Figure 8a shows the net present value of double-pressure recuperated ORCs, depending on the inlet temperature of the brine. Comparison of figures $3 \mathrm{~b}$ and $8 \mathrm{a}$ shows that the NPV increases when another pressure level is added for all investigated fluids, except for R218. The maximum pressure in the optimal cycle for that fluid, R218, is much higher than the critical point. The fit between the brine cooling curve and the working fluid heating curve in a temperature-heat diagram is very good, so adding another pressure level does not improve the cycle performance. The addition of an extra pressure level is especially profitable for cycles in which the evaporation temperature in the single-pressure cycle is much lower than the critical temperature (isobutane and R245fa). The effect of the second pressure level is relatively small for the other fluids.

The specific cost of double-pressure recuperated ORCs is shown in figure 8b. Comparison with figure $4 \mathrm{~b}$ shows that the specific overnight investment cost increases by a small amount (up to $5 \%$ ) if an extra pressure level is added. The net electric power output increases too as shown in figure 8c. The effect of the increased net electric power output is more important than the increased investment cost of the ORC, due to the high investment cost of the wells; the increased investment cost of the ORC is small relative to the total investment cost.

In the remainder of this paper, only the results of single-pressure cycles will be shown, but the trends are similar for double-pressure cycles.

\subsection{Influence of the electricity price}

Figure 9a shows the NPV of ORCs powered by geothermal heat as a function of the electricity price. The NPV increases strongly with increasing electricity price, because not only the price of the electricity increases, but the amount of electricity produced increases too. The latter effect is shown in figure $9 \mathrm{~b}$, which 


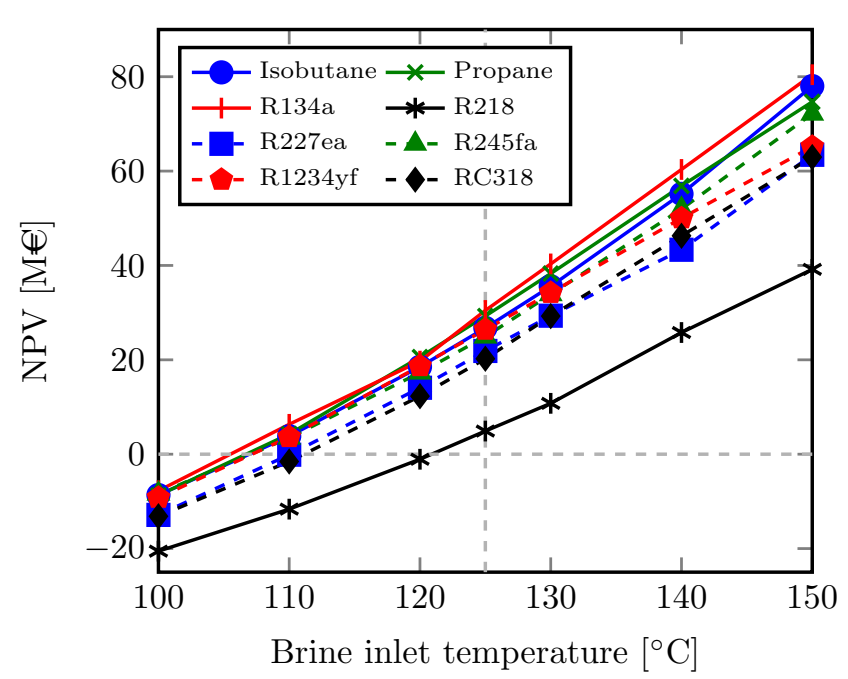

(a) Net present value

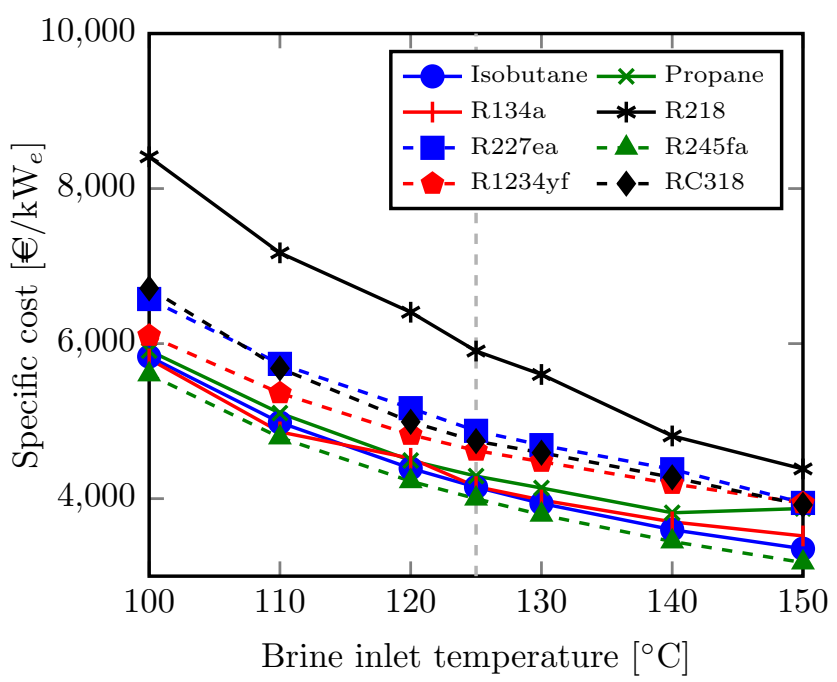

(b) Specific cost

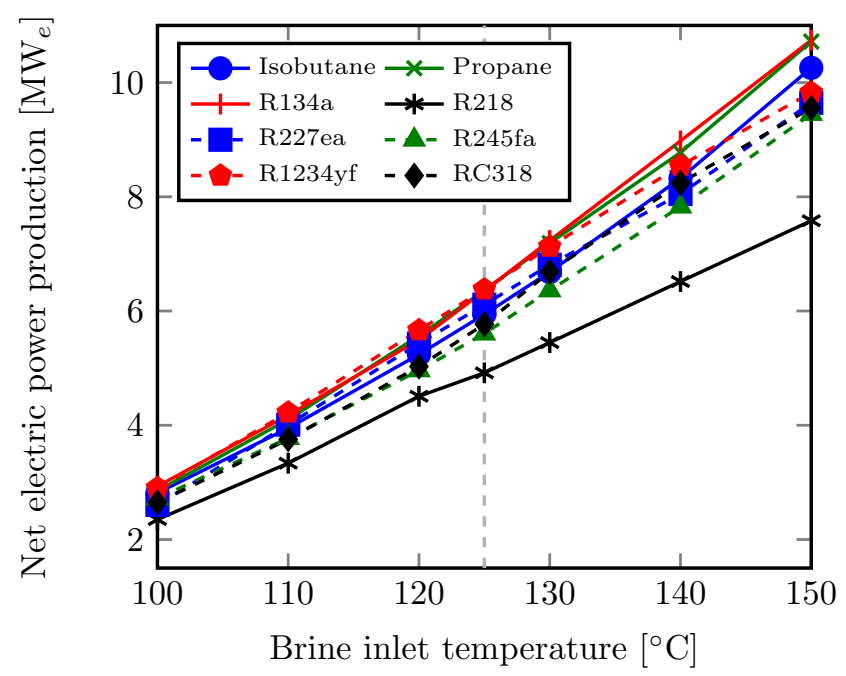

(c) Net electric power production

Figure 8: Net present value (a) and specific cost (b) of a double-pressure recuperated ORC powered by geothermal heat, depending on the inlet temperature of the brine.

shows the net electric power produced. The higher electric power production is explained by the fact that a higher electricity price, and thus a higher income during the lifetime of the power plant, allows to invest more in a more efficient power plant. This increase in electric power production follows from a decreasing condenser temperature, decreasing pinch-point-temperature differences and a decreasing heat-source-outlet temperature, so more heat is added to the cycle. This results also in a higher specific cost of the ORC, which is shown in figure 10 .

\subsection{Influence of the discount rate and electricity price evolution}

Figures 11a and 11b show the net present value as a function of the discount rate and the annual electricity price evolution, respectively. The trend of a decreasing discount rate and an increasing electricity price 


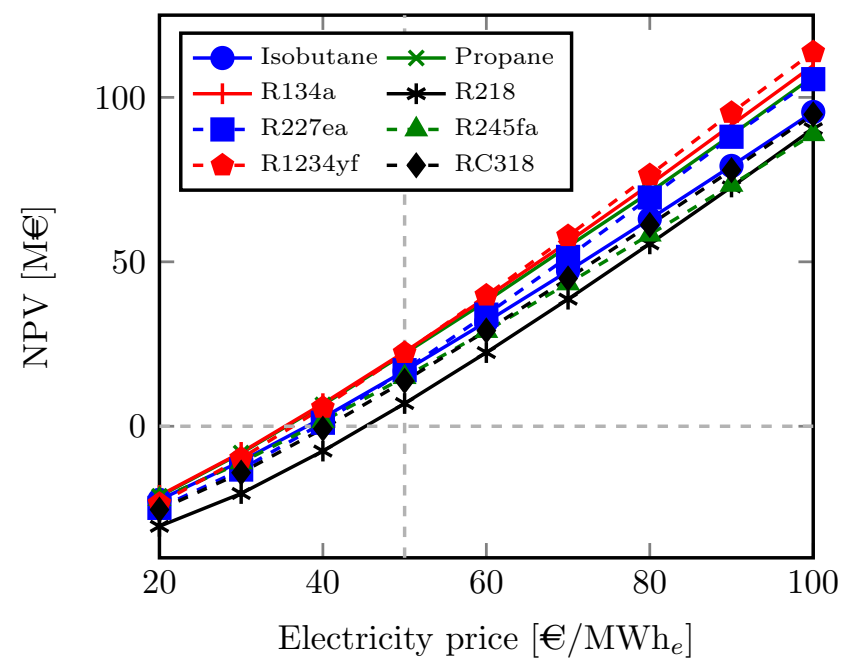

(a) NPV

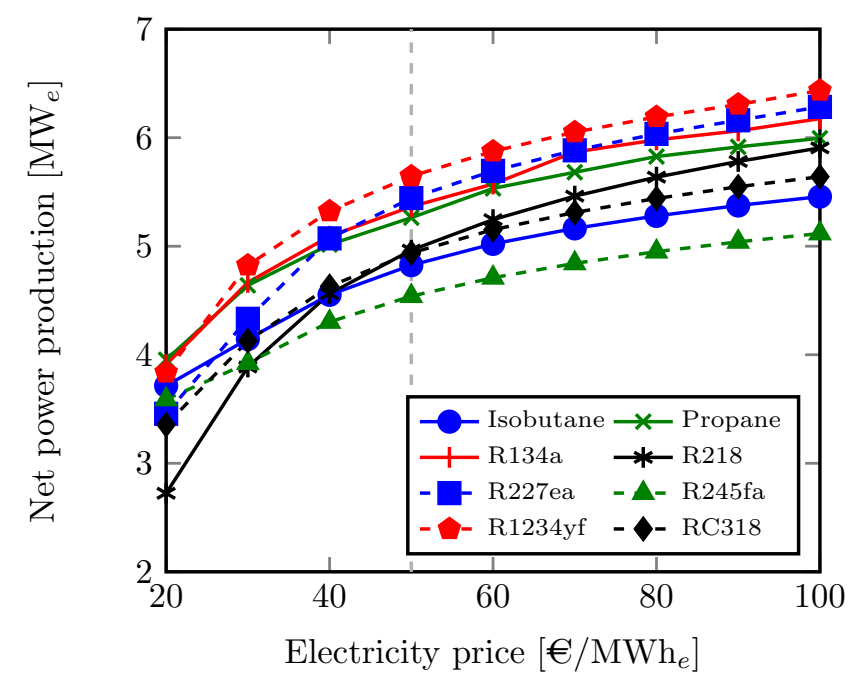

(b) Net electric power production

Figure 9: Net present value (a) and net electric power production (b) of a single-pressure, recuperated ORC powered by geothermal heat, depending on the electricity price.

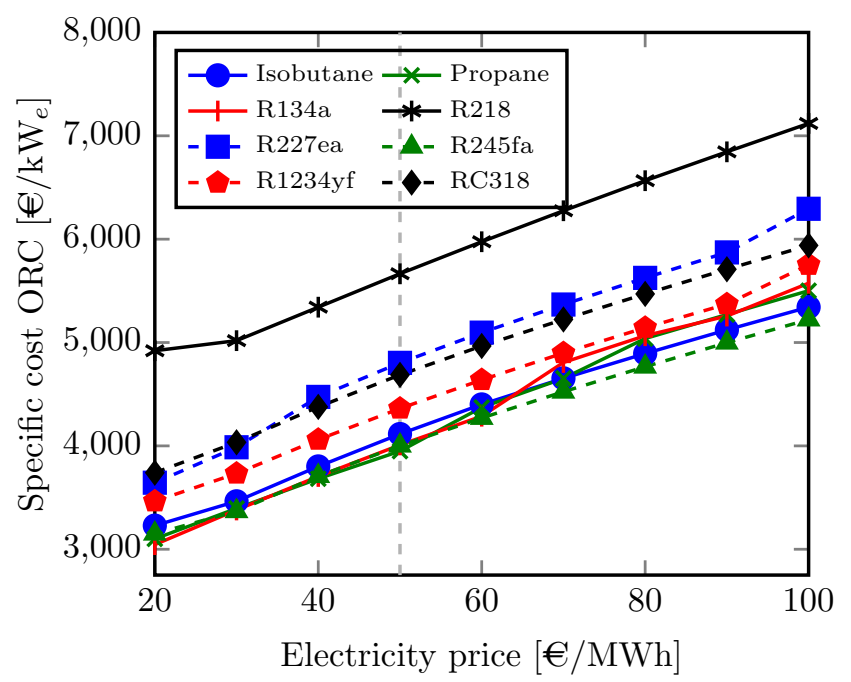

Figure 10: Specific cost of a single-pressure, recuperated ORC powered by geothermal heat, depending on the electricity price.

evolution are analogous to the effect of an increasing electricity price (figure 9a). The effect of the discount rate is very strong, due to the high investment and low operational costs.

\section{Conclusions}

A system optimization of an air-cooled ORC powered by geothermal heat is performed in this paper. The cycle parameters of the ORC, the geometry of the heat exchangers and the geometry of the air-cooled heat exchanger are optimized together in order to obtain the maximum net present value of the installation.

It is shown that the brine inlet temperature, the brine outlet temperature, the electricity price, discount 


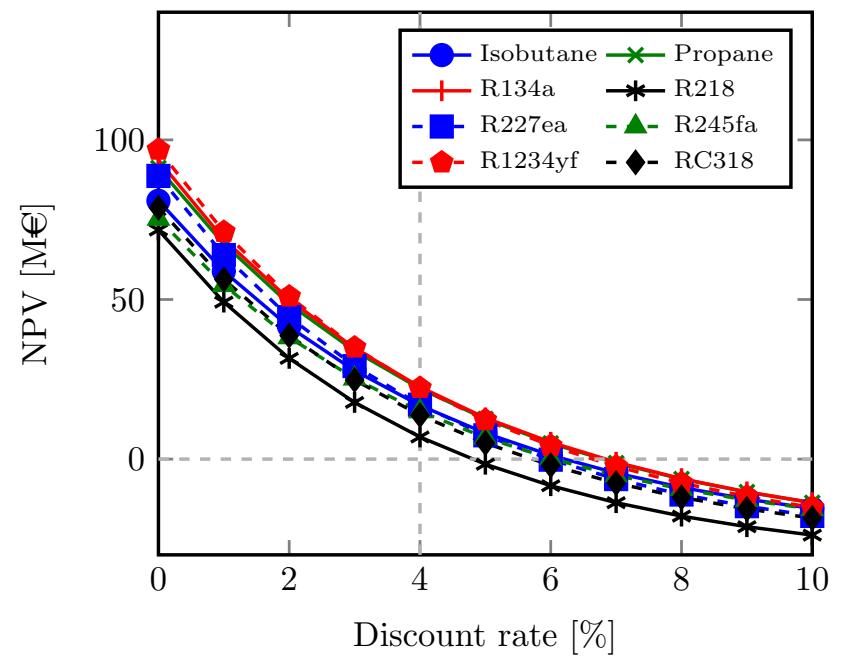

(a) Discount rate

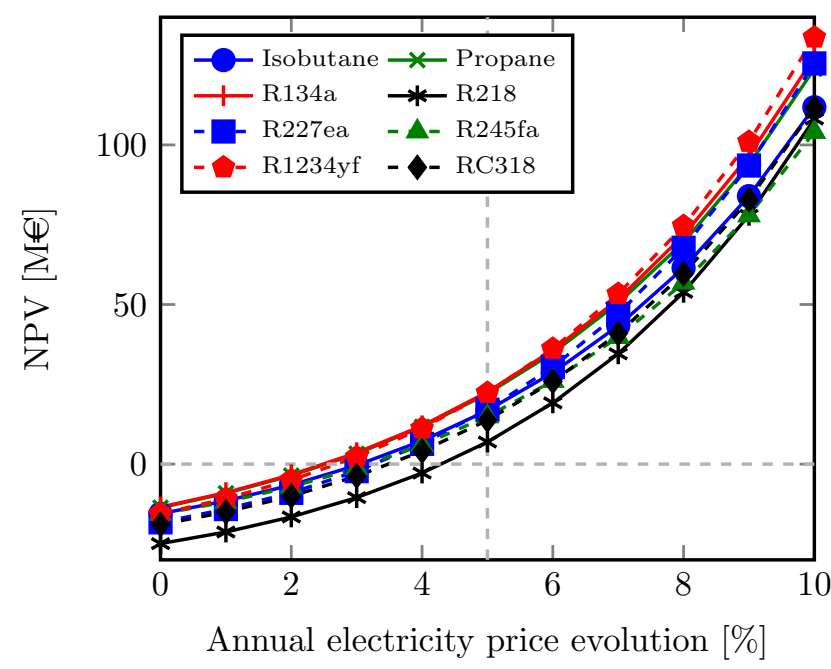

(b) Annual lectricity price evolution

Figure 11: Net present value of a single-pressure, recuperated ORC powered by geothermal heat, depending on the discount rate (a) or the electricity price evolution (b).

rate and electricity price evolution have a strong influence on the net present value of the geothermal power plant. For cycles with dry fluids it is always useful to include a recuperator because this heat exchanger decreases the cooling load. A recuperator is advantageous for cycles with wet fluids only when the brine outlet temperature is constrained.

The performance (thermodynamic and economic) of single-pressure subcritical cycles in which the evaporation temperature is "much" lower than the critical temperature can improve strongly by addition of an extra pressure level, although the specific cost of the ORC increases.

The air-cooled condenser is a very important component. It has a strong influence on the efficiency of the power plant through the condensing temperature and the power consumption of the fans and it accounts for a large part of the investment cost of the ORC (about $80 \%$ in the case study). 


\section{Nomenclature}

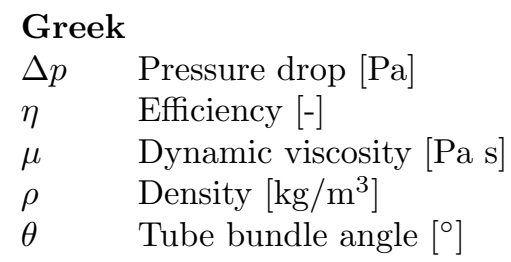

\section{Roman}

A Surface area $\left[\mathrm{m}^{2}\right]$

C Cost [€]

$d_{o} \quad$ Tube outside diameter $[\mathrm{m}]$

$D_{s} \quad$ Shell diameter [m]

$f \quad$ Friction factor [-]

$f \quad$ Correction factor [-]

$h \quad$ Specific enthalpy $[\mathrm{J} / \mathrm{kg}]$

$H \quad$ Fin height $[\mathrm{m}]$

$i \quad$ Discount rate [\%]

I Income [€]

$l_{c} \quad$ Baffle cut length $[\mathrm{m}]$

$L_{b} \quad$ Baffle spacing $[\mathrm{m}]$

$L_{t} \quad$ Length of the tubes (ACC) [m]

$\dot{m} \quad$ Mass flow $[\mathrm{kg} / \mathrm{s}]$

$N \quad$ Number of full load hours [-]

NPV Net present value [€]

$\mathrm{Nu} \quad$ Nusselt number [-]

$\begin{array}{ll}n_{\text {tubes }} & \text { Number of tubes }[-] \\ \text { ORC } & \text { Organic Rankine cycle } \\ p & \text { Price }[€] \\ p_{t} & \text { Tube pitch }[\mathrm{m}] \\ \dot{Q} & \text { Volume flow }\left[\mathrm{m}^{3} / \mathrm{s}\right] \\ R e & \text { Reynolds number }[-] \\ S & \text { Fin pitch [m] } \\ t & \text { Time [year] } \\ V_{A m i n} & \text { Velocity at minimum flow area }[\mathrm{m} / \mathrm{s}] \\ \dot{W} & \text { Mechanical power }[\mathrm{kW}] \\ W_{s} & \text { Tube small width }[\mathrm{m}] \\ W_{l} & \text { Tube large width }[\mathrm{m}]\end{array}$




$\begin{array}{ll}\text { Sub-and } & \text { superscripts } \\ \text { air } & \text { Air } \\ \text { drilling } & \text { Drilling } \\ E & \text { Equipment } \\ \text { el } & \text { Electrical } \\ E P C & \text { Engineering, Procurement and Construction } \\ \text { fan } & \text { Fan } \\ \text { I } & \text { Installation } \\ \text { in } & \text { Inlet } \\ \text { is } & \text { Isentropic } \\ \text { LT } & \text { lifetime } \\ M & \text { Material } \\ \text { net } & \text { Nett } \\ \text { OM } & \text { Operation and maintenance } \\ \text { ORC } & \text { ORC } \\ & \\ \text { out } & \text { Outlet } \\ P & \text { Pressure } \\ \text { pump } & \text { Pump } \\ T & \text { Temperature } \\ \text { turbine } & \text { Turbine } \\ & \end{array}$

\section{Acknowledgments}

Daniël Walraven is supported by a VITO doctoral grant.

\section{References}

[1] J. Tester, B. Anderson, A. Batchelor, D. Blackwell, R. DiPippo, E. Drake, J. Garnish, B. Livesay, M. Moore, K. Nichols, The Future of Geothermal Energy: Impact of Enhanced Geothermal Systems (EGS) on the United States in the 21st Century, Tech. Rep., Massachusetts Institute of Technology, Massachusetts, USA, 2006.

[2] Y. Dai, J. Wang, L. Gao, Parametric optimization and comparative study of organic Rankine cycle (ORC) for low grade waste heat recovery, Energy Conversion and Management 50 (3) (2009) 576-582.

[3] B. Saleh, G. Koglbauer, M. Wendland, J. Fischer, Working fluids for low-temperature organic Rankine cycles, Energy 32 (7) (2007) 1210-1221.

[4] D. Walraven, B. Laenen, W. Dhaeseleer, Comparison of thermodynamic cycles for power production from low-temperature geothermal heat sources, Energy Conversion and Management 66 (2013) 220-233.

[5] M. Astolfi, M. C. Romano, P. Bombarda, E. Macchi, Binary ORC (Organic Rankine Cycles) power plants for the exploitation of medium-low temperature geothermal sources-Part A: Thermodynamic optimization, Energy 66 (2014) 423-434.

[6] S. Quoilin, S. Declaye, B. F. Tchanche, V. Lemort, Thermo-economic optimization of waste heat recovery Organic Rankine Cycles, Applied Thermal Engineering 31 (14) (2011) 2885-2893.

[7] M. Astolfi, M. C. Romano, P. Bombarda, E. Macchi, Binary ORC (Organic Rankine Cycles) power plants for the exploitation of medium-low temperature geothermal sources-Part B: Techno-economic optimization, Energy 66 (2014) 435-446.

[8] H. Madhawa Hettiarachchi, M. Golubovic, W. M. Worek, Y. Ikegami, Optimum design criteria for an organic Rankine cycle using low-temperature geothermal heat sources, Energy 32 (9) (2007) 1698-1706.

[9] A. Franco, M. Villani, Optimal design of binary cycle power plants for water-dominated, medium-temperature geothermal fields, Geothermics 38 (4) (2009) 379-391.

[10] D. Walraven, B. Laenen, W. D'haeseleer, Optimum configuration of shell-and-tube heat exchangers for the use in lowtemperature organic Rankine cycles, Energy Conversion and Management 83 (C) (2014) 177-187.

[11] C.-C. Wang, Y.-J. Chang, Y.-C. Hsieh, Y.-T. Lin, Sensible heat and friction characteristics of plate fin-and-tube heat exchangers having plane fins, International Journal of Refrigeration 19 (4) (1996) 223-230.

[12] C.-C. Wang, C.-J. Lee, C.-T. Chang, S.-P. Lin, Heat transfer and friction correlation for compact louvered fin-and-tube heat exchangers, International journal of heat and mass transfer 42 (11) (1998) 1945-1956.

[13] C.-C. Wang, W.-H. Tao, C.-J. Chang, An investigation of the airside performance of the slit fin-and-tube heat exchangers, International Journal of Refrigeration 22 (8) (1999) 595-603.

[14] C. Wang, W. Fu, C. Chang, Heat transfer and friction characteristics of typical wavy fin-and-tube heat exchangers, Experimental Thermal and Fluid Science 14 (2) (1997) 174-186. 
[15] L. Yang, H. Tan, X. Du, Y. Yang, Thermal-flow characteristics of the new wave-finned flat tube bundles in air-cooled condensers, International Journal of Thermal Sciences 53 (2012) 166-174.

[16] Y.-J. Chang, C.-C. Wang, A generalized heat transfer correlation for Iouver fin geometry, International Journal of heat and mass transfer 40 (3) (1997) 533-544.

[17] Y.-J. Chang, K.-C. Hsu, Y.-T. Lin, C.-C. Wang, A generalized friction correlation for louver fin geometry, International Journal of Heat and Mass Transfer 43 (12) (2000) 2237-2243.

[18] R. M. Manglik, A. E. Bergles, Heat transfer and pressure drop correlations for the rectangular offset strip fin compact heat exchanger, Experimental Thermal and Fluid Science 10 (2) (1995) 171-180.

[19] E. Macchi, A. Perdichizzi, Efficiency prediction for axial-flow turbines operating with nonconventional fluids, Journal for Engineering for Power 103 (4) (1981) 718-724.

[20] J. R. Thome, Engineering Databook III, Wolverine Tube, Inc., 2010.

[21] B. Petukhov, V. Popov, Theoretical calculation of heat exchange and frictional resistance in turbulent flow in tubes of an incompressible fluid with variable physical properties(Heat exchange and frictional resistance in turbulent flow of liquids with variable physical properties through tubes), High Temperature 1 (1963) 69-83.

[22] V. Gnielinski, New equations for heat and mass-transfer in turbulent pipe and channel flow, International Chemical Engineering 16 (2) (1976) 359-368.

[23] A. Premoli, D. Difrancesco, A. Prina, A dimensionless correlation for the determination of the density of two-phase mixtures, Termotecnica,(Milan) 25 (1) (1971) 17-26.

[24] D. Chisholm, Pressure gradients due to friction during the flow of evaporating two-phase mixtures in smooth tubes and channels, International Journal of Heat and Mass Transfer 16 (2) (1973) 347-358.

[25] M. M. Shah, An improved and extended general correlation for heat transfer during condensation in plain tubes, HVAC\&R Research 15 (5) (2009) 889-913.

[26] H. Craig, H. Cox, Performance estimation of axial flow turbines, Proceedings of the Institution of Mechanical Engineers 185 (1) (1970) 407-424.

[27] W. D'haeseleer, Synthesis on the Economics of Nuclear Energy, Study for the European Commission, DG Energy, available at: http://ec.europa.eu/energy/nuclear/forum/doc/final_report_dhaeseleer/synthesis_economics_nuclear_ 20131127-0.pdf, 2013.

[28] IEA, Technology Roadmap: Geothermal Heat and Power, Tech. Rep., International Energy Agency, 2011.

[29] R. Smith, Chemical process design and integration, Wiley New York, 2005.

[30] R. K. Sinnott, Chemical Engineering Design, Butterworth-Heinemann, 1999.

[31] G. Towler, R. Sinnott, Chemical engineering design: principles, practice and economics of plant and process design, Butterworth-Heinemann, 2008.

[32] J. Andersson, J. Åkesson, M. Diehl, CasADi - A symbolic package for automatic differentiation and optimal control, in: S. Forth, P. Hovland, E. Phipps, J. Utke, A. Walther (Eds.), Recent Advances in Algorithmic Differentiation, vol. 87 of Lecture Notes in Computational Science and Engineering, Springer Berlin Heidelberg, 297-307, 2012.

[33] C. Büskens, D. Wassel, The ESA NLP Solver WORHP, in: Modeling and Optimization in Space Engineering, Springer, 85-110, 2013

[34] E. Lemmon, M. Huber, M. Mclinden, NIST Reference Fluid Thermodynamic and Transport Properties REFPROP, The National Institute of Standards and Technology (NIST), version 8.0, 2007.

\section{Appendix A. Turbine-stage-efficiency prediction}

The turbine-stage-efficiency prediction is given as a function of the dimensional parameter $X=\ln \left[\sqrt{\left.\dot{Q}_{\text {out }}\right|_{\text {is }}} /\left.\Delta h\right|_{i s} ^{1 / 4}\right]$ and the specific volume variation across the turbine stage in an isentropic process $Y=\left.\dot{Q}_{\text {out }}\right|_{\text {is }} / \dot{Q}_{\text {in }} . \dot{Q}_{\text {in }}$ and $\left.\dot{Q}_{\text {out }}\right|_{\text {is }}$ are the volume flow rate at the inlet of the turbine stage and outlet of the turbine stage in case of an isentropic turbine expansion, respectively. $\left.\Delta h\right|_{i s}$ is the enthalpy drop across the turbine stage in case of an isentropic turbine expansion.

Equation (A.1) gives the expression for the curve-fit of the efficiency prediction in Macchi and Perdichizzi [19].

$$
\begin{aligned}
\eta_{\text {turbine }}= & 0.892-9.0810^{-2} X-1.0310^{-2} Y \\
& -7.7310^{-2} X^{2}+9.7910^{-5} Y^{2}-9.6110^{-4} X Y \\
& -2.3410^{-2} X^{3}+3.0210^{-3} X^{2} Y+9.6810^{-5} Y^{2} X \\
& -2.5510^{-3} X^{4}+1.4910^{-3} X^{3} Y+1.7710^{-4} X^{4} Y
\end{aligned}
$$




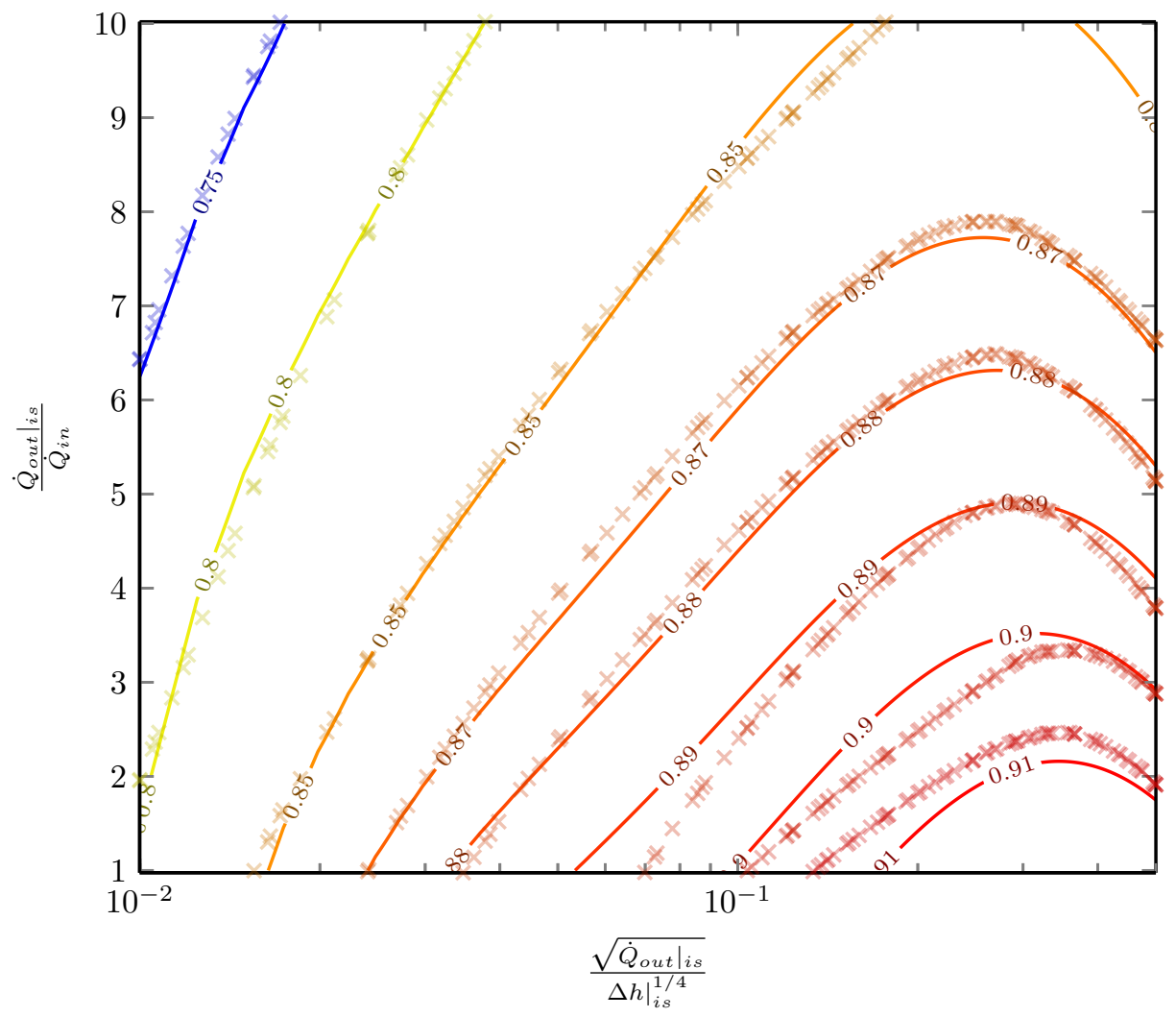

Figure A.1: Curve fit $(-)$ of the efficiency prediction for a turbine stage according to equation (A.1). Data points (x) from Macchi and Perdichizzi [19].

\section{Appendix B. Definition investment cost}

In this paper only the engineering, procurement \& construction cost $\left(C_{E P C}\right)$ is taken into account, but the total investment cost consists also of other parts. Neither owner costs nor provisions for contingency nor financing costs (or interest during construction) are considered here. The most widely used delineation can be found in D'haeseleer [27]:

- Total investment cost

- Overnight construction cost

* Owner's cost

* Engineering, procurement \& construction cost

* Contingency provision

- Interest during construction 